HEALTH PSYCHOLOGY REPORT · VOLUME 8(2), 2020 ORIGINAL ARTICLE
Anna R. Egbert (D)

$1,2 \cdot \mathrm{A}, \mathrm{B}, \mathrm{C}, \mathrm{D}, \mathrm{E}, \mathrm{F}$

Agnieszka Pluta $\mathbb{D}$

$2,3 \cdot A, B, E, G$

Marta Sobańska (D)

$2 \cdot \mathrm{A}, \mathrm{B}, \mathrm{E}, \mathrm{G}$

Natalia Gawron (D)
Bogna Szymańska-Kotwica

$5 \cdot \mathrm{B}$

Emilia Łojek (D)

$2 \cdot \mathrm{A}, \mathrm{B}, \mathrm{D}, \mathrm{G}$

Harmonia Group

$2,3,5,6,7,8 \cdot \mathrm{B}, \mathrm{D}$

$4 \cdot A, B, E, G$

\title{
HIV-related decreased brain activity during a semantic memory task is reflected in spontaneous brain functional connectivity
}

\begin{abstract}
BACKGROUND
The primary goal was to examine HIV-related changes in brain activation during a semantic memory task. The secondary goal was to assess whether the functional connectivity of the brain regions showing altered activity during the semantic memory task is related to HIV serostatus.
\end{abstract}

\section{PARTICIPANTS AND PROCEDURE}

The total group of 17 male subjects, aged on average 44 years, included $8 \mathrm{HIV+/CART+}$ and 9 demographically matched healthy comparators. Participants completed Famous Names Recognition task-functional magnetic resonance imaging (fMRI) and resting state fMRI.

\section{RESULTS}

We found an effect of HIV status on brain activation during the semantic memory task, despite comparable accuracy and reaction time across groups. Compared to healthy individuals, in HIV+ participants recognition of famous names elicited less activity in the fronto-striatal network, particularly in the left caudate nucleus $(p=.049)$, left inferior frontal gyrus $(p=.047)$, left thalamus $(p=.031)$ and right thalamus $(p=.047)$, as well as in the left middle occipital gyrus $(p=.028)$. Although an effect of HIV status on functional connectivity of the brain regions showing altered activity during semantic memory task was not observed, resting-state activation of those regions was significantly correlated with performance on cognitive domains of attention, executive functioning, psychomotor speed and semantic skills.

\section{CONCLUSIONS}

Our findings suggest the presence of functional brain network reorganization in HIV+/cART+ patients, particularly in subcortical regions of the fronto-striatal network, in the absence of neurocognitive decline.

\section{KEY WORDS}

neurocognitive; cART; fMRI; functional brain connectivity; hand

ORGANIZATION - 1: Faculty of Medicine, University of British Columbia, Vancouver, Canada - 2: Faculty of Psychology,

University of Warsaw, Warsaw, Poland · 3: Institute of Physiology and Pathology of Hearing, World Hearing Center, Kajetany, Poland · 4: Department of Adult Clinical Psychology, Institute of Psychology, The Maria Grzegorzewska University, Warsaw, Poland · 5: The Central Hospital for Infectious Diseases, Warsaw, Poland · 6: The College of Medicine, The Ohio State University, Columbus, OH, USA . 7: The Cleveland Clinic, Cleveland, OH, USA. 8: Institute of Psychiatry and Neurology, Warsaw, Poland

authors' Contributions - A: Study design - B: Data collection - C: Statistical analysis - D: Data interpretation .

E: Manuscript preparation · F: Literature search · G: Funds collection

CORRESPONDING AUTHOR - Anna R. Egbert, Ph.D., Faculty of Medicine, University of British Columbia, 2329 West Mall, Vancouver, BC, V6T 1Z4 Canada, e-mail: anna.r.egbert@gmail.com

to Cite this ARticle - Egbert, A. R., Pluta, A., Sobańska, M., Gawron, N., Szymańska-Kotwica, B., Łojek, E., \& Harmonia

Group (2020). HIV-related decreased brain activity during a semantic memory task is reflected in spontaneous brain

functional connectivity. Health Psychology Report, 8(2), 120-135. https://doi.org/10.5114/hpr.2020.94720

RECEIVED 19.02.2020 • REVIEWED 03.03.2020 • ACCEPTED 29.03.2020 • PUBLISHED 04.05.2020 


\section{BACKGROUND}

Human immunodeficiency virus (HIV) affects almost 37 million people worldwide, with over 1.8 million new cases each year (UNAIDS, 2017). Despite advances in treatment, immunological and neurological complications in HIV continue to pose a great challenge. It is estimated that about a half of infected individuals are at risk of developing HIV-associated neurocognitive disorder (HAND) (Heaton et al., 2010). HAND symptoms include deficits in learning, memory, attention, psychomotor speed and/or executive functions (Antinori et al., 2007; Heaton et al., 2011; Woods, Moore, Weber, \& Grant, 2009). While combination antiretroviral therapy (cART) can successfully slow down the development and progression of HAND, complete eradication of the virus is not possible (Gray et al., 2014). Most antiretroviral drugs do not cross the blood-brain barrier, leaving the brain as one of the major reservoirs of HIV (Nath, 2015). Thus, not surprisingly neurocognitive impairments are still prevalent among HIV+ individuals treated with cART (McArthur \& Brew, 2010). In addition, there has been a growing body of research demonstrating functional brain changes (i.e., regional increases and decreases in activation) in HIV infection which occur even prior to the cognitive decline (Hakkers et al., 2017; Melrose, Tinaz, Castelo, Courtney, \& Stern, 2008). It is possible that the observed changes in brain activation may reflect functional compensatory mechanisms aimed at maintaining normal cognitive functioning in spite of HIV-related neurodegeneration (Hakkers et al., 2017).

Abnormal patterns of brain activity are detected even in early and asymptomatic stages of HIV infection using blood-oxygen-level dependent functional magnetic resonance imaging (BOLD fMRI) (Hakkers et al., 2017). For this reason, it is considered to be a promising tool that might aid in diagnosis of HIV-related neurocognitive deficits. The two most commonly used methods of fMRI are task-based fMRI (t-fMRI) and resting-state fMRI (RS-fMRI). Task-based fMRI enables brain activity to be tracked during cognitive task performance (Arthurs \& Boniface, 2002). Previous t-fMRI studies with HIV+ individuals (Du Plessis et al., 2014; Hakkers et al., 2017; Melrose et al., 2008) have demonstrated regional hypo- (i.e. decreased) or hyper- (i.e. increased) activation in this group (in comparison to healthy comparators) during execution of memory, motor or attention tasks, despite good behavioral performance (in terms of accuracy and reaction time). In the reviewed studies, HIV-related functional abnormalities were found to be most pronounced within the fronto-striatal network (FSN), which refers to pathways that connect frontal areas with the basal ganglia, particularly in the regions of the left inferior frontal gyrus and left caudate nucleus $(\mathrm{Du}$
Plessis et al., 2014; Hakkers et al., 2017). As frontostriatal network activation is strongly associated with executive task performance (Hakkers et al., 2017), it has been argued that changes within this particular brain network are most likely to account for executive dysfunctions observed in HIV infection (Melrose et al., 2008). Task-related brain activation, however, constitutes only a small increase from the baseline energetic consumption during brain spontaneous activity (Fox \& Raichle, 2007). Intrinsic brain activation can be assessed with the RS-fMRI (Biswal, Zerrin Yetkin, Haughton, \& Hyde, 1995). In detail, RS-fMRI examines spatial synchronization of spontaneous brain activity (i.e., low frequency fluctuations in BOLD signal) in the absence of overt task performance (Biswal et al., 1995). Previous RS-fMRI studies have reported attenuated fronto-striatal connectivity (particularly between the dorsolateral prefrontal cortex and caudate/thalamic regions) in HIV+ individuals (Ipser et al., 2015; Ortega, Brier, \& Ances, 2015), which converges with findings from t-fMRI studies. Recently, decreased functional connectivity has been observed between frontal and parietal regions in $\mathrm{HIV+/cART+}$ individuals vs. healthy comparators (Egbert et al., 2018). Interestingly, no differences in subcortical connectivity (left and right caudate nucleus, putamen, pallidum and thalamus) were noted between HIV+ participants on long-term cART and matched healthy comparators (Janssen et al., 2017).

The vast majority of fMRI research, to date, has focused on examining either task-related brain activation (t-fMRI) or intrinsic activation 'at rest' (RSfMRI). Studies combining data acquired with both methods are notably lacking, limiting the current understanding of the brain functional mechanisms in HIV infection. Previous reports in the healthy adult population indicated a strong association between task-related and intrinsic brain activation patterns (Cole, Bassett, Power, Braver, \& Petersen, 2014; Tavor et al., 2016). Not surprisingly, therefore, current research typically investigates brain activation only in one of these states. Nonetheless, as argued by Geerligs, Rubinov, and Henson (2015), it is difficult to differentiate stable patterns of activity from those that are transient without studying individuals in multiple cognitive states. This is especially true considering the poor reliability of RS measurements with the scan length below 10-15 min (Birn et al., 2013; Gordon et al., 2017). For this reason, combining data on functional alterations during cognitive task performance with data on resting state functional connectivity might help to achieve more reliable results. Learning from these findings, we appreciate that application of both approaches, i.e., t-fMRI and RS-fMRI, will provide a more thorough approach to uncover enduring brain functional architecture changes introduced by HIV infection. Therefore, in
Brain activity in HIV infection 
Anna R. Egbert, Agnieszka Pluta, Marta Sobańska, Natalia Gawron, Bogna SzymańskaKotwica,

Emilia Łojek, Harmonia Group this study, we integrated measurements from both task-based and resting-state fMRI with the goal to (i) identify signatures of HIV-related functional changes (based on measurements of brain activity during execution of a low-effort semantic memory task), and (ii) evaluate the effect of HIV infection on the relationship between RS functional connectivity of regions showing altered activation during task execution and neurocognitive performance. Based on existing literature, we expected $\mathrm{HIV}+/ \mathrm{cART}+$ individuals to show increased brain activation within the fronto-striatal network during recognition of famous names (semantic memory task). Furthermore, we hypothesized to observe an association between executive function scores and the intensity of spontaneous local functional connectivity in brain regions revealing altered activation during cognitive task performance.

\section{PARTICIPANTS AND PROCEDURE}

\section{PARTICIPANTS}

The present study was conducted within the framework of the Harmonia-3 project investigating the effect of aging on cognitive and chemosensory functioning of the brain in HIV infection (PI: Łojek, E.; grant\# UMO2012/06/M/H56/00316). A total of 34 Polish male subjects ( $11 \mathrm{HIV}+$ and $23 \mathrm{HIV}-$; 24 to 66 years) took part in both resting-state and task-based fMRI scanning sessions. HIV+ participants were recruited from the patients of the Central Hospital for Infectious Diseases in Warsaw. The following inclusion criteria were applied: infection through sexual intercourse (men who have sex with men); min. 1 year since infection; cART treatment; systematic medical control and stabilized medical counts for min. 6 months. Demographically matched HIV- comparators were recruited from local organizations for MSM (i.e., men who have sex with men). In both groups, the exclusion criteria included: deficits in learning; education below high school level; presence of mental disorders (such as psychosis, anxiety, depression) and presence or history of physical illnesses (such as head trauma, cancers, diabetes, untreated hypertension, amnestic disorders or neurological disorders). Subjects with either inferior quality fMRI data (i.e. motion artifacts) or low accuracy in the fMRI task (i.e. < 70\%) were excluded from the study. Following application of the groupmatching procedure, a final sample of 17 participants (8 HIV+ and $9 \mathrm{HIV}-; 28$ to 63 years), matched for age and education, was retained for further analysis. All subjects received financial compensation for participation. Any human data included in this manuscript were obtained in compliance with regulations of the Ethics Committee of the University of Warsaw.

\section{DATA COLLECTION}

\section{Clinical and treatment-related variables}

The following clinical and treatment characteristics were retrieved from the medical records of the HIV+ participants: date of HIV detection; dates of HAART implementation and alterations; CD4 count at detection and current; viral load at detection and current. In the comparator group, HIV-negative serostatus was confirmed from a blood sample within two weeks prior to assessment.

\section{Neuropsychological assessment}

The following comprehensive set of standardized neuropsychological tests was administered in a pseudo-randomized fixed order described previously (Egbert et al., 2018). Mini-Mental State Examination (MMSE) was used as a screening tool for global state cognitive function (Folstein, Folstein, \& McHugh, 1975; Polish adapt.: Stańczak, 2010). The Visual Memory Span Test, also called the Block-Tapping Task (Corsi, 1972), was used to examine spatial attention and working memory. During this test the examiner taps the blocks (numbered from 1 to 9) in a particular order. The subject's task is to pay attention to what the examiner is doing and then to repeat the same action, by tapping the blocks in the same order (visual memory forward) or in the reverse order (visual memory backward). The California Verbal Learning Test (CVLT; Delis, Kramer, Kaplan, \& Ober, 2000; Polish adapt.: Łojek, Stańczak, Delis, Kramer, \& Ober, 2010) indicated the ability to learn (and memorize) verbal information. The Ruff Figural Fluency Test (RFFT; Ruff, 1996; Polish adapt.: Łojek \& Stańczak, 2005) was used to assess fluency and capacity for set shifting and divergent thinking. The Color Trails Test (CTT; D’Elia \& Satz, 2000; Polish adapt.: Łojek \& Stańczak, 2012) measured visual attention, psychomotor abilities and executive processing. The Grooved Pegboard Test (Matthews \& Klove, 1964) was used to assess manual dexterity, psychomotor speed and coordination. Two subtests of the Wechsler Adult Intelligence Scale-Revised (WAIS-R; Wechsler, 1981; Polish adapt.: Brzeziński et al., 2004) were used: Digit Span to assess working memory; and Vocabulary for language abilities and verbal fluency. The Wisconsin Card Sorting Test (WCST; Heaton, 1981; Polish adapt.: Jaworowska, 2002) was employed to test abstract thinking and set-shifting ability. The Verbal Fluency Test (Polish adapt.: Szepietowska \& Gawda, 2011) examined fluency and word production. Additionally, we used the Center for Epidemiological Studies Depression Scale (CES-D; Eaton, Smith, Ybarra, Muntaner, \& Tien, 2004; Polish adapt.: Koziara, 2016), a self-reported measure sensitive to depressive thoughts and behaviors within the 
last two weeks, where a score $\geq 16$ out of 60 indicates significant depressive symptoms. Finally, the Patient's Assessment of Own Functioning Inventory (PAOFI; Chelune, Heaton, \& Lehman, 1986), a subjective neurocognitive complaint questionnaire, was administered to participants in order to assess their self-assessed functioning in five domains: memory, language and communication, sensory-motor skills, and higher level cognitive and intellectual functions.

\section{Cognitive domains}

To facilitate further analysis, neurocognitive measures were organized into cognitive domains according to their sensitivity to specific functions. Five predetermined domains included: 1) Attention - CTT trail 1, Visual Memory Span (forward, backward), and WAIS Digit Span (forward, backward); 2) Memory - CVLT list A trials 1-5 total, list A trial 5, long delay free recall, recognition hits; 3) Executive - RFFT total unique design, Verbal Fluency total, WCST categories completed, breaks, perseverative errors, and CTT trail 2; 4) Psychomotor - CTT trial 1 and 2, PEG dominant hand input and output time, and RFFT total unique designs; 5) Semantic - WAIS Vocabulary and Verbal Fluency total. To evaluate outcome in each domain, raw scores from tests were transformed first into $Z$-scores (based on the Harmonia-3 project entire cohort; $N=200$ ) and then into $t$-scores (based on the project's non-HIV comparator group; $N=100$ ), with higher scores indicating better performance. Cognitive domain scores were used for HAND diagnosis in the HIV+ group (Antinori et al., 2007).

\section{Imaging acquisition and processing}

Image acquisition. Imaging was performed on a $3 \mathrm{~T}$ Siemens TIM TRIO VB17 whole-body MR scanner with a 32-channel head matrix coil at the Bioimaging Research Center of the Institute of Physiology and Pathology of Hearing in Kajetany, Poland. T1-weighted structural images of the whole brain were acquired with the following acquisition parameters: $\mathrm{TE}=2.21 \mathrm{~ms}, \mathrm{TR}=1900 \mathrm{~ms}, \mathrm{TI}=900 \mathrm{~ms}$, flip angle $=9^{\circ}$, field of view $=260 \mathrm{~mm} \times 288 \mathrm{~mm}$, slice thickness $=0.9 \mathrm{~mm}$, number of slices $=208$, image matrix $=290 \times 320$, which gives an isotropic voxel size of $0.9 \times 0.9 \times 0.9 \mathrm{~mm}$, pixel bandwidth $=200 \mathrm{~Hz} /$ pix, $\mathrm{iPAT}=2$, and $\mathrm{TA}=5 \mathrm{~min}$. RS BOLD fMRI $(\mathrm{TR}=2000 \mathrm{~ms}$, TE $=25 \mathrm{~ms}$, voxel dimension $=3 \times 3 \times 3 \mathrm{~mm}$ isotropic, imaging matrix $=64 \times 64$, slice thickness $=3 \mathrm{~mm}, 41$ slices with no gap, number of reference slice $=1$, acquisition time $=8.08 \mathrm{~min}$, with a total of 240 frames) was performed directly after MPRAGE. During RS-fMRI, participants were instructed to relax with their eyes open and not to think of anything in particular. Functional images were obtained using GR-EPI (40 axial slices with resolution $3.25 \times 3.25 \times 3.3 \mathrm{~mm}, \mathrm{TR}=2000 \mathrm{~ms}$, $\mathrm{TE}=25 \mathrm{~ms}, \mathrm{FA}=90$, matrix $64 \times 64, \mathrm{iPAT}=2$ ). A total of two functional runs were then acquired: the $1^{\text {st }}$ run with 186 volumes $(\mathrm{TA}=6: 20)$ and the $2^{\text {nd }}$ run with 126 volumes $(\mathrm{TA}=4: 20)$.

\section{Task-based fMRI}

Task. The Famous Names Recognition Task (FNRT; Douville et al., 2005) is a low-effort semantic memory task in which participants are asked to distinguish between names of famous and non-famous people. All names in the FNRT should have a high rate of identification (> 90\%). A modified version of the FNRT, suitable for Polish participants, was used in the present study. Task stimuli included Polish names only, selected from an original pool of names on the basis of their high identification rate (determined during the pilot study). The final list comprised $50 \mathrm{fa}-$ mous and 50 non-famous names.

Paradigm and procedure. While in the fMRI scanner, participants viewed either famous or non-famous names (one at a time; displayed for 4 seconds each) and were asked to decide whether the name is or is not famous (i.e. left button on the response pad if the name was famous and right button if the name was non-famous). Names were randomly interspersed with a picture of a centrally placed cross (control condition). Participants were instructed to fixate on the cross and not to press any button. The present study employed an event-related design in which stimuli of different types (i.e. famous, nonfamous and cross) were randomly interleaved. The experiment consisted of two sessions in total. The first session was longer and included 90 stimulus pictures (30 famous names, 30 non-famous names and 30 crosses). The second session included 60 stimulus pictures (20 famous names, 20 non-famous names and 20 crosses). Total time was approximately $6 \mathrm{~min}$ for the first session and $4 \mathrm{~min}$ for the second session.

Preprocessing. Preprocessing was performed using SPM12 software (Wellcome Department of Imaging Neuroscience London, 2014) and according to the standard procedure (Ashburner et al., 2017) which included the following steps: slice timing, realignment, coregistration, segmentation, normalization and smoothing. First, functional images were corrected for differences in slice timing and head motion artifacts. Then, functional images were coregistered to the structural image and normalized to the Montreal Neurological Institute (MNI) standard space. Finally, the resulting images were smoothed with a $6 \times 6 \times 6 \mathrm{~mm}$ FWHM (full width at half maximum) Gaussian kernel.

Postprocessing. The individual task-related activation was evaluated using a general linear model (GLM). The design matrix contained three predictors of interest (famous names, non-famous names, cross)
Brain activity in HIV infection 
Anna R. Egbert, Agnieszka Pluta, Marta Sobańska, Natalia Gawron, Bogna SzymańskaKotwica,

Emilia Łojek, Harmonia Group and additional predictors of no interest (estimated body-head movement artifacts and constant level of activation). Functional data from both sessions were combined in the design matrix. The BOLD signal was modeled with a box-car function convolved with a canonical hemodynamic response function. Beta values of each predictor in the design matrix were estimated. Famous vs. non-famous names (i.e. F > NF) contrast was defined for each subject.

Quality assurance. In order to retain high quality data, we used the measures of absolute and relative motion as well as framewise displacement. We used the following threshold as exclusion criteria. We calculated absolute motion values in SPM 12 and used the threshold of $2 \mathrm{~mm}$. Relative motion was analyzed using the Artifact Detection Tools (ART) toolbox (https://www.nitrc.org/projects/artifact_detect/) in SPM12. Analysis was based on the extracted voxelwise time series for each participant separately. The threshold of relative movement for each time point was set at $0.5 \mathrm{~mm}$. FD was calculated for translation and rotation separately as previously described by Di and Biswal (2015). The threshold for FD of mean translation/rotation was set at $0.2 \mathrm{~mm} / 0.2 \mathrm{de}-$ grees and of maximum translation/rotation at $1.5 \mathrm{~mm} / 1.5$ degrees. Out of the final sample used for this study $(N=17)$, none of the participants have exceeded the abovementioned motion thresholds. Thus, no participants were excluded due to excess motion during fMRI scanning session.

Regions of interest selection. A total of 15 regions of interest (ROIs) were examined for the $\mathrm{F}>\mathrm{NF}$ names contrast (Table 1).

All ROIs were chosen a priori. Nine ROIs (i.e. left middle frontal gyrus, bilateral precuneus, left and right middle temporal gyrus, left middle occipital gyrus, left caudate nucleus, left and right hippocampus, left cerebellum VII-VIII) and their coordinates were selected based on the findings of previous fMRI studies with the Famous Names Recognition Task (Rao et al., 2015; Woodard et al., 2009). Six other ROIs (i.e. left dorsolateral prefrontal cortex, left ventromedial prefrontal cortex, left dorsal anterior cingulate cortex, left inferior frontal gyrus, left and right thalamus) included regions belonging to the frontostriatal network, the functioning of which is said to

Table 1

Selected regions of interest (ROIs) with coordinates

\begin{tabular}{|c|c|c|c|c|}
\hline \multirow[t]{2}{*}{ Region } & \multirow[t]{2}{*}{ BA } & \multicolumn{3}{|c|}{ MNI coordinates } \\
\hline & & $\mathrm{x}$ & $\mathrm{y}$ & z \\
\hline \multicolumn{5}{|l|}{ Frontal lobe } \\
\hline L Middle frontal gyrus & 6,8 & -22 & 13 & 51 \\
\hline L Dorsolateral prefrontal cortex & 9 & -44 & 27 & 43 \\
\hline L Ventromedial prefrontal cortex & 32 & -6 & 50 & -1 \\
\hline L Dorsal anterior cingulate cortex & 32 & -2 & 30 & 27 \\
\hline L Inferior frontal gyrus (IFG) & 47 & -40 & 31 & -13 \\
\hline \multicolumn{5}{|l|}{ Parietal / Temporal lobe } \\
\hline B Precuneus, posterior cingulate & 7,23 & -2 & -55 & 26 \\
\hline L Middle temporal, angular gyri & 21,39 & -47 & -55 & 19 \\
\hline R Middle temporal, angular gyri & 21,39 & 52 & -56 & 16 \\
\hline \multicolumn{5}{|l|}{ Occipital lobe } \\
\hline L Middle occipital gyrus & - & -34 & -77 & 0 \\
\hline \multicolumn{5}{|l|}{ Subcortical } \\
\hline L Caudate nucleus (caudate) & - & -10 & 10 & 5 \\
\hline L Hippocampus & - & -31 & -27 & -11 \\
\hline R Hippocampus & - & 31 & -27 & -11 \\
\hline L Thalamus & 50 & -12 & -12 & 6 \\
\hline R Thalamus & 50 & 11 & -12 & 6 \\
\hline L Cerebellum (VII-VIII) & - & -21 & -68 & -32 \\
\hline
\end{tabular}

Note. L - left; R - right; B - bilateral; BA - Brodmann area; MNI - Montreal Neurological Institute 

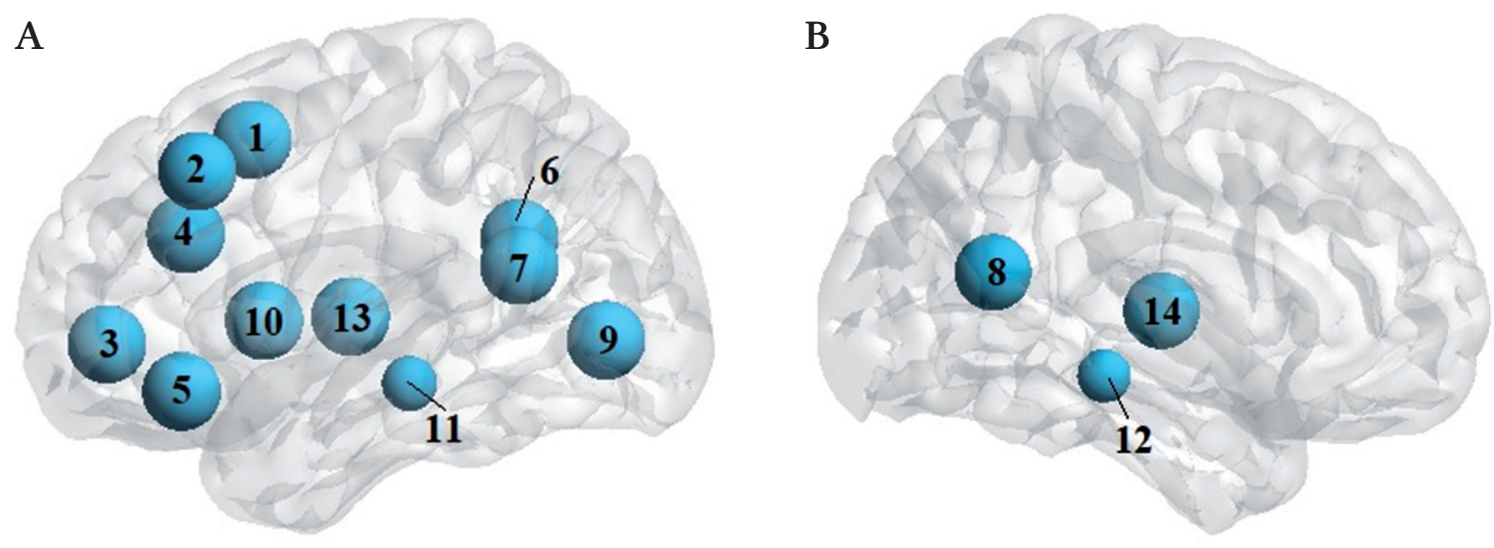

Brain activity in HIV infection

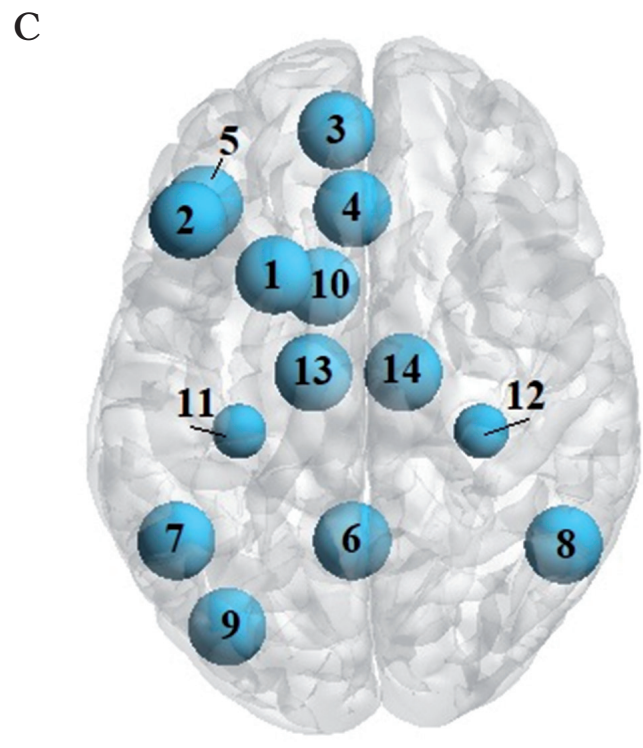

Figure 1. Location, shape and size of all chosen regions of interest. Left lateral $(A)$, right lateral (B) and superior $(C)$ views of the brain. Numbers from 1 to 14 stand for: 1 - left middle frontal gyrus; 2 - left dorsolateral prefrontal cortex, 3 - left ventromedial prefrontal cortex, 4 - left dorsal anterior cingulate cortex, 5 - left inferior frontal gyrus, 6 - bilateral precuneus/posterior cingulate, 7 - left middle temporal/angular gyrus, 8 - right middle temporal/angular gyrus, 9 - left middle occipital gyrus, 10 - left caudate nucleus, 11 - left hippocampus, 12 - right hippocampus, 13 - left thalamus, 14 - right thalamus. Cerebellum (VII-VIII) is not indicated in the figure.

be especially compromised in HIV+ individuals (Du Plessis et al., 2014). Their center coordinates were taken from either of two functional atlases (Lacadie, Fulbright, Rajeevan, Constable, \& Papademetris, 2008; Dosenbach et al., 2010). Graphic representations of all ROIs are depicted in Figure 1.

\section{$R S-f M R I$}

RS-fMRI data preprocessing. We preprocessed the data using SPM12 (Statistical Parametric Mapping) software and customized image processing routines written in MatLab8.5.1. The implemented preprocessing pipeline was previously described (Egbert et al., 2018). Data were cleaned with temporal filtering at 0.01-0.08 Hz consistent with previous literature (Di \& Biswal, 2015).

Regions of interest selection. ROIs were selected based on the results of task-based fMRI analysis. Only those ROIs that revealed significantly different effects in HIV+ vs. HIV- groups for F-NF names contrasts were retained for further analysis of restingstate functional connectivity.

\section{DATA ANALYSES}

\section{Task-based fMRI data analysis}

Reaction time (RT) and accuracy (\% correct) in the FNRT were recorded. Using SPM12, individual contrast maps (i.e. F > NF names) were analyzed with group-level statistics of the independent samples $t$-test in order to determine whether differences in signals evoked with cognitive processing were related to HIV serostatus. The results were thresholded at voxel level $p<.001$ (uncorrected) and at cluster level $p<.05$ (FWE corrected).

\section{Regions of interest analysis}

All 15 ROIs were constructed as spheres centered around predetermined coordinates with radius of either $7 \mathrm{~mm}$ (L and R hippocampus) or $10 \mathrm{~mm}$ (other ROIs). For each individual, the mean percentage signal change in each ROI was extracted ( $F>$ NF names contrast) using the MarsBar 0.44 tool for SPM (Brett, Anton, Valabregue, \& Poline, 2002). 
Anna R. Egbert, Agnieszka Pluta, Marta Sobańska, Natalia Gawron, Bogna SzymańskaKotwica,

Emilia Łojek, Harmonia Group

\section{$R S-f M R I$ data analysis}

Preprocessed RS-fMRI data without temporal filtering were entered into voxel-based analysis in the REST toolbox (http://restfmri.net/forum/index. php?q=rest). We calculated regional homogeneity (ReHo) based on Kendall's coefficient of concordance (KCC-ReHo). Data were first detrended in order to remove the linear trend. Then, we set the band pass filter at $0.01-0.08 \mathrm{~Hz}$, cluster size at 27 voxels and implemented a data-driven inclusive mask. We standardized the obtained individual ReHo maps by dividing them by the mean within the defined mask in order to obtain a standardized measure of ReHo (i.e., mReHo). The standardized regional homogeneity values for ROIs were extracted using the MarsBar 0.44 tool for SPM (Bret et al., 2002).

\section{Statistical analysis}

Normality of demographic, cognitive and task (t-fMRI) performance variables was tested using the Shapiro-Wilk test. Bivariate analyses of continuous variables were performed using either the independent samples $t$-test (normal distribution) or the Mann-Whitney $U$ test (non-normal distribution). Categorical variables were tested using the chi-square test. To assess between-group (HIV+ vs. HIV-) differences in regional brain activation during the semantic memory task, linear regression (with age as a covariate and HIV status as a predictor) was performed for each ROI. Only ROIs with significantly different between-group effects for $\mathrm{F}>\mathrm{NF}$ names contrasts were retained for further analysis of resting-state functional connectivity.

\section{RESULTS}

\section{SAMPLE CHARACTERISTICS}

A sample of 17 Polish male subjects $(\mathrm{HIV}+=8$, HIV- $=9)$ with the mean age of 44 years $(S D=8.66)$ was retained for analysis. Between-group comparisons did not reveal any significant differences in age, years of education, economic status, sexual behavior or weekly alcohol consumption (Table 2).

In the HIV+ group, $100 \%$ of subjects were infected through sexual transmission (i.e. men who have sex with men). The mean time since HIV diagnosis was

Table 2

Characteristics of the studied sample

\begin{tabular}{|c|c|c|c|}
\hline & $\mathrm{HIV}+$ & HIV- & $p$ \\
\hline \multicolumn{4}{|l|}{ Demographics } \\
\hline Male, $n(\%)$ & $8(100)$ & $9(100)$ & \\
\hline Age, $M(S D)$ & $44.50(10.55)$ & $43.78(7.22)$ & $.873 a$ \\
\hline Caucasian White, $n(\%)$ & $8(100)$ & $9(100)$ & \\
\hline Sexual behavior, $n(\%)$ & & & $.235 c$ \\
\hline Only homosexual & $6(75)$ & $5(55.6)$ & \\
\hline Mainly homosexual & $1(12.5)$ & $0(0)$ & \\
\hline Bisexual & $1(12.5)$ & $1(11.1)$ & \\
\hline Only heterosexual & $0(0)$ & $3(3.3)$ & \\
\hline Education years, $M(S D)$ & $16.13(2.42)$ & $17.17(2.72)$ & $.416 a$ \\
\hline Employment status, $n(\%)$ & & & $.269 c$ \\
\hline Employed & $7(87.5)$ & $9(100)$ & \\
\hline Unemployed & $1(12.5)$ & $0(0)$ & \\
\hline Income, $n(\%)$ & & & $.179 c$ \\
\hline Above national average & $3(42.9)$ & $7(77.8)$ & \\
\hline Below national average & $2(28.6)$ & $2(22.2)$ & \\
\hline National minimum & $2(28.6)$ & $0(0)$ & \\
\hline Alcohol $^{*}, M(S D)$ & $2.62(3.29)$ & $3.50(2.45)$ & $.264 b$ \\
\hline
\end{tabular}

Note. ${ }^{*}$ weekly consumption; a - independent $t$-test; $\mathrm{b}$ - Mann-Whitney $U$ test; c - chi-square test. 
6 years $(S D=2.93,1-10$ years $)$. On average, HIV+ participants began treatment within 1 to 2 years after HIV diagnosis. At the time of the study, all HIV+ participants were being treated with cART and were aviremic. They had significantly suppressed viral loads $(M=40.75, S D=2.12)$ and increased $C D 4$ values $(M=579.00, S D=142.96)$. More clinical and laboratory data on the HIV+ group are shown in Table 3.

Table 3

Results of neurocognitive and affective functioning assessment

\begin{tabular}{|c|c|c|c|}
\hline & $\mathrm{HIV}+$ & HIV- & $p$ \\
\hline$M M S E, M(S D)$ & $29.63(0.52)$ & $29.11(1.05)$ & $.310 \mathrm{~b}$ \\
\hline \multicolumn{4}{|l|}{ Visual Memory Span, $M(S D)$} \\
\hline Forward & $7.88(1.73)$ & $9.67(1.58)$ & $.041 a^{*}$ \\
\hline Backward & $8.00(1.85)$ & $8.67(1.41)$ & $.414 \mathrm{a}$ \\
\hline \multicolumn{4}{|l|}{ CVLT, $M(S D)$} \\
\hline List A Trials 1-5 & $53.25(12.74)$ & $57.11(5.44)$ & $.446 \mathrm{~b}$ \\
\hline List A Trial 5 & $12.25(2.71)$ & $13.44(0.88)$ & $.267 \mathrm{a}$ \\
\hline Long delay free recall & $11.13(3.09)$ & $12.67(1.66)$ & $.212 \mathrm{a}$ \\
\hline Recognition hits & $15.00(0.76)$ & $14.89(1.05)$ & $.808 \mathrm{a}$ \\
\hline RFFT - total unique designs, $M(S D)$ & $80.75(30.64)$ & $96.56(18.68)$ & $.213 a$ \\
\hline \multicolumn{4}{|l|}{$\mathrm{CTT}, M(S D)$} \\
\hline Trial 1 - time in $s$ & $37.88(9.83)$ & $38.57(15.06)$ & $.913 a$ \\
\hline Trial 2 - time in $s$ & $81.38(26.87)$ & $75.99(22.60)$ & $.660 \mathrm{a}$ \\
\hline \multicolumn{4}{|l|}{ Grooved Pegboard Test, $M(S D)$} \\
\hline DH input time (s) & $63.63(14.36)$ & $70.03(21.01)$ & $.529 b$ \\
\hline NDH input time (s) & $24.00(3.46)$ & $21.28(2.63)$ & $.086 \mathrm{a}$ \\
\hline DH output time (s) & $68.38(9.69)$ & $73.28(7.48)$ & $.258 \mathrm{a}$ \\
\hline NDH output time (s) & $24.25(3.85)$ & $21.91(3.67)$ & $.219 \mathrm{a}$ \\
\hline \multicolumn{4}{|l|}{ WAIS Digit Span, $M(S D)$} \\
\hline Forward & $6.88(1.25)$ & $6.89(2.71)$ & $.990 \mathrm{a}$ \\
\hline Backward & $6.00(1.77)$ & $7.56(3.78)$ & $.305 a$ \\
\hline WAIS Vocabulary, $M(S D)$ & $44.00(8.70)$ & $50.67(9.18)$ & $.146 \mathrm{a}$ \\
\hline Verbal Fluency - total score, $M(S D)$ & $136.00(29.95)$ & $122.67(24.12)$ & $.326 a$ \\
\hline \multicolumn{4}{|l|}{ WCST, $M(S D)$} \\
\hline Total perseverative errors & $11.13(9.22)$ & $9.33(9.87)$ & $.661 b$ \\
\hline Breaks & $0.25(0.71)$ & $0.11(0.33)$ & $.864 b$ \\
\hline Categories completed & $5.88(0.35)$ & $5.78(0.67)$ & $1.000 \mathrm{~b}$ \\
\hline \multicolumn{4}{|l|}{ PAOFI, $M(S D)$} \\
\hline Memory & $41.13(3.44)$ & $40.33(4.09)$ & $.674 a$ \\
\hline Language/communication & $44.50(2.07)$ & $40.56(5.83)$ & $.086 a$ \\
\hline Use of hands & $9.38(0.92)$ & $9.33(1.41)$ & $.675 b$ \\
\hline Sensory-perceptual & $14.25(0.89)$ & $13.33(1.94)$ & $.312 b$ \\
\hline Cognitive functions & $40.38(3.29)$ & $39.78(4.52)$ & $.763 a$ \\
\hline
\end{tabular}

Brain activity in HIV infection

(Table 3 continues) 
Anna R. Egbert, Agnieszka Pluta, Marta Sobańska, Natalia Gawron, Bogna SzymańskaKotwica,

Emilia Łojek, Harmonia Group

\begin{tabular}{|c|c|c|c|}
\hline & $\mathrm{HIV}+$ & HIV- & $p$ \\
\hline \multicolumn{4}{|l|}{ STAI, $M(S D)$} \\
\hline Anxiety State & $32.86(9.62)$ & $33.00(5.61)$ & $.971 \mathrm{a}$ \\
\hline Anxiety Trait & $36.43(8.85)$ & $36.67(8.54)$ & $.345 a$ \\
\hline CESD-R - total score, $M(S D)$ & $5.43(4.72)$ & $5.44(6.02)$ & $.957 b$ \\
\hline \multicolumn{4}{|l|}{ Cognitive Domains } \\
\hline Attention & $48.04(5.73)$ & $51.86(9.67)$ & $.345 a$ \\
\hline Executive & $51.59(5.66)$ & $52.37(4.63)$ & $.759 a$ \\
\hline Memory & $46.15(9.95)$ & $51.03(4.77)$ & $.290 \mathrm{~b}$ \\
\hline Psychomotor & $50.91(6.60)$ & $50.65(7.14)$ & $.923 b$ \\
\hline Semantic & $50.57(10.16)$ & $53.32(8.70)$ & $.558 \mathrm{a}$ \\
\hline
\end{tabular}

Note. MMSE - Mini-Mental State Examination; CVLT - California Verbal Learning Test; RFFT - Ruff Figural Fluency Test; CTT Color Trails Test; DH - dominant hand; NDH - non-dominant hand; WAIS - Wechsler Adult Intelligence Scale; WCST - Wisconsin Card Sorting Test; PAOFI - Patient Assessment of Own Functioning; STAI - State-Trait Anxiety Inventory; CESD-R - Center for Epidemiological Studies Depression Scale; a - independent samples $t$-test; $\mathrm{b}-$ Mann-Whitney $U$ test. ${ }^{*} p<.05$.

Table 4

Characteristics of the HIV+ group (clinical and laboratory data)

\begin{tabular}{|c|c|}
\hline Parameter & $\mathrm{HIV}+$ \\
\hline Way of infection - MSM, $n(\%)$ & $8(100)$ \\
\hline $\begin{array}{l}\text { Years since HIV diagnosis, } \\
M(S D) ; \text { range }\end{array}$ & $6.00(2.93) ; 1-10$ \\
\hline $\begin{array}{l}\text { Age when diagnosed, } M(S D) ; \\
\text { range }\end{array}$ & $\begin{array}{c}38.00(9.41) \\
23-55\end{array}$ \\
\hline $\begin{array}{l}\text { Time between diagnosis and } \\
\text { start of treatment (years), } \\
M(S D) ; \text { range }\end{array}$ & $1.75(1.83) ; 0-5$ \\
\hline Receiving cART, $n(\%)$ & $8(100)$ \\
\hline $\begin{array}{l}\text { Years since cART, } M(S D) ; \\
\text { range }\end{array}$ & $4.25(3.01) ; 1-9$ \\
\hline $\begin{array}{l}\text { Years on current cART, } M(S D) \text {; } \\
\text { range }\end{array}$ & $2.50(1.60) ; 1-5$ \\
\hline CPE Index, $M(S D) ;$ range & $7.12(1.36) ; 5-9$ \\
\hline \multicolumn{2}{|l|}{ HAND, $n(\%)$} \\
\hline No HAND, $n(\%)$ & $7(87.5)$ \\
\hline Asymptomatic HAND & $1(12.5)$ \\
\hline CD4 nadir, $M(S D)$ & $204.63(153.62)$ \\
\hline CD4 current, $M(S D)$ & $579.00(142.96)$ \\
\hline Highest viral load, $M(S D)$ & $\begin{array}{c}83100.37 \\
(102350.44)\end{array}$ \\
\hline Current viral load, $M(S D)$ & $40.75(2.12)$ \\
\hline
\end{tabular}

Note. MSM - men who have sex with men; CPE - Central Nervous System Penetration Effectiveness.

\section{NEUROCOGNITIVE AND AFFECTIVE FUNCTIONING}

Performance of HIV+ and HIV- individuals on chosen measures of neurocognitive functioning was largely comparable. With the sole exception of lower visual memory span forward in the $\operatorname{HIV}+(M=7.88$, $S D=1.73)$ compared to the HIV- group $(M=9.67$, $S D=1.58)(t(21)=2.23, p=.041)$, no between-group differences in cognitive domains (i.e. Attention, Memory, Executive functions, Psychomotor and Semantic skills), self-reported cognitive or affective functioning were noted (Table 4). Nonetheless, despite similar performance in both groups, results of neurocognitive assessment indicated that one of our HIV+ participants met the criteria for mild HAND (Antinori et al., 2007), with scores being one standard deviation below the age-appropriate norm only in the domains of Memory $(t=39.49, S D=1.05)$ and Semantic skills $(t=36.58$, $S D=1.34$ ), with a simultaneous lack of decline in Attention, Executive and Psychomotor domains. Subjectively, the participant did not notice any decline in daily functioning (as indicated by PAOFI). Moreover, additional data distribution analysis showed that this subject was not an outlier on any task-related brain activity or resting state functional connectivity measures. Thus, we retained him for further analyses.

\section{TASK-FMRI}

\section{Task performance}

No between-group differences in accuracy (\% correct) or reaction time (in ms) were found (Table 5). 


\begin{tabular}{|c|c|c|c|}
\hline & $\mathrm{HIV}+$ & HIV- & \multirow[t]{2}{*}{$p$} \\
\hline & $M(S D)$ & $M(S D)$ & \\
\hline \multicolumn{4}{|l|}{ Session 1} \\
\hline Famous (\% correct) & $95.00(6.67)$ & $97.41(4.01)$ & $.401 \mathrm{~b}$ \\
\hline Non-famous (\% correct) & $95.63(5.63)$ & $95.56(5.83)$ & $.786 b$ \\
\hline Famous (RT, ms) & $1097(192)$ & $1174(147)$ & $.369 a$ \\
\hline Non-famous (RT, ms) & $1129(179)$ & $1161(178)$ & $.255 \mathrm{a}$ \\
\hline \multicolumn{4}{|l|}{ Session 2} \\
\hline Famous (\% correct) & $97.92(2.48)$ & $97.41(4.34)$ & $.958 b$ \\
\hline Non-famous (\% correct) & $96.25(3.54)$ & $97.22(5.07)$ & $.336 b$ \\
\hline Famous (RT, ms) & $1391(216)$ & $1533(271)$ & $.712 \mathrm{a}$ \\
\hline Non-famous (RT, ms) & $1370(261)$ & $1599(344)$ & $.146 a$ \\
\hline \multicolumn{4}{|l|}{ Total (Session 1 and 2) } \\
\hline Famous (\% correct) & $95.25(5.01)$ & $96.67(3.87)$ & $.616 b$ \\
\hline Non-famous (\% correct) & $97.25(1.83)$ & $97.33(3.61)$ & $.485 b$ \\
\hline Famous (RT, ms) & $1113(180)$ & $1168(158)$ & $.515 \mathrm{a}$ \\
\hline Non-famous (RT, ms) & $1381(235)$ & $1566(284)$ & $.166 a$ \\
\hline
\end{tabular}

Note. a - independent samples $t$-test; b - Mann-Whitney $U$ test; RT - response time.

Both HIV+ and HIV- individuals had very high accuracy $(>95 \%)$ on the Famous Names Recognition Task.

\section{Semantic memory brain activation}

Activation of brain resources in response to the famous vs. non-famous names task was significantly related to HIV status (accounting for age). In particular, famous names recognition triggered significantly lower brain activation in HIV+ than in HIV- individuals in the left caudate nucleus $(B=-.35, p=.049)$, left inferior frontal gyrus $(B=-.34, p=.047)$, left thalamus $(B=-.30, p=.031)$, right thalamus $(B=-.35$, $p=.047)$, and left middle occipital gyrus $(B=-.24$, $p=.028$ ) (Table 6). HIV status alone explained $20-30 \%$ of variability in the noted decreased brain activation.

Regions of interest showing differential activation during semantic memory task in HIV+ vs. HIVgroup are presented in Figure 2.

\section{RS-FMRI}

Resting state regional homogeneity

We found no statistically significant effects of HIV serostatus on smoothed regional homogeneity (smReHo) values in the left caudate $(B=-.03, p=.079)$, left inferior frontal gyrus $(B=-.01, p=.701)$, left thalamus $(B=-.01, p=.792)$, right thalamus $(B=.02$, $p=.525)$ or left occipital $(B=.05, p=.153)$ (Table 6$)$.

Resting-state functional connectivity and neurocognitive performance

Relationship between smReHo and cognitive domains. $\mathrm{HIV}+$ individuals showed significant positive relationships between smReHo values in left thalamus and Attention scores (rho $=.76, p=.028$ ); and between smReHo values in right thalamus and Attention (rho $=.81, p=.015)$, Executive ( $\mathrm{rho}=.71, p=.047)$ and Psychomotor (rho $=.71, p=.047$ ) scores. HIVindividuals showed significant negative relationships between smReHo values in left caudate and Semantic Skills (rho $=-.68, p=.042$ ); and between smReHo values in left IFG and Attention (rho $=-.75, p=.020$ ) and Executive (rho $=-.70, p=.036$ ) scores. Results of correlational analyses are presented in Table 7.

\section{DISCUSSION}

This study examined task-based brain activity, spontaneous brain functional connectivity in relation to neurocognitive outcomes in HIV+/HAART+ vs. HIVindividuals. All HIV+/HAART + participants were
Brain activity in HIV infection 
Table 6

Results of linear regression analysis with HIV status as a predictor and regional task-related (t-fMRI) vs. restingstate (RS-fMRI) brain activation as dependent variables

Anna R. Egbert, Agnieszka Pluta, Marta Sobańska, Natalia Gawron, Bogna SzymańskaKotwica, Emilia Łojek, Harmonia Group

\begin{tabular}{|c|c|c|c|c|}
\hline \multirow[t]{2}{*}{ Region of interest } & \multicolumn{2}{|c|}{$t-f M R I$} & \multicolumn{2}{|c|}{ RS-fMRI } \\
\hline & $B$ & $p$ & $B$ & $p$ \\
\hline L Middle frontal gyrus & .16 & .322 & - & - \\
\hline L Dorsolateral prefrontal cortex & .23 & .237 & - & - \\
\hline L Ventromedial prefrontal cortex & .07 & .719 & - & - \\
\hline L Dorsal anterior cingulate cortex & .30 & .149 & - & - \\
\hline L Inferior frontal gyrus (IFG) & .34 & .047 & .01 & .701 \\
\hline B Precuneus, posterior cingulate & .43 & .176 & - & - \\
\hline L Middle temporal, angular gyri & .28 & .216 & - & - \\
\hline R Middle temporal, angular gyri & .30 & .129 & - & - \\
\hline L Middle occipital gyrus & .24 & .028 & .05 & .153 \\
\hline L Caudate nucleus & .35 & .049 & .03 & .079 \\
\hline L Hippocampus & .15 & .266 & - & - \\
\hline R Hippocampus & .14 & .316 & - & - \\
\hline L Thalamus & .30 & .031 & .01 & .792 \\
\hline R Thalamus & .35 & .047 & .02 & .525 \\
\hline L Cerebellum VII-VIII & .16 & .433 & - & - \\
\hline
\end{tabular}

Note. Age as a covariate. All coefficients are unstandardized.
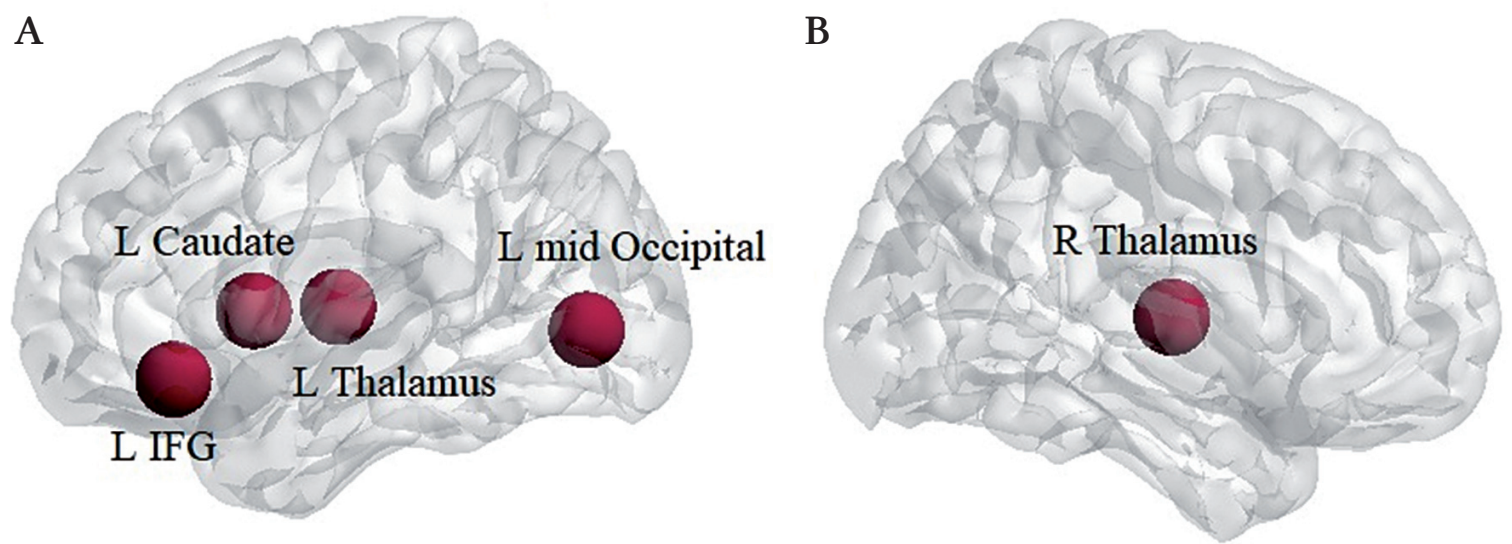

Figure 2. Regions of interest with differential task-related activation in HIV+ vs. HIV- groups. Left (A) and right (B) lateral views of the brain.

well-functioning and had a comparable cognitive status to healthy participants. As demonstrated by the results of cognitive assessment, our HIV+/HAART+ individuals did not show any marked deficits in the domains of attention, memory, executive, psychomotor or semantic skills when compared to their HIVcounterparts; nor did they report any significant problems in cognitive or affective functioning. This stands in contrast to previous reports, according to which executive and learning/memory dysfunctions remain characteristic features of HIV infection in spite of antiretroviral treatment (Heaton et al., 2011; Woods et al., 2009). The absence of marked impairments in the above-mentioned cognitive domains in our HIV+ sample can, at least partly, be attributed to restrictive inclusion criteria applied in this study (such as HAART treatment, low viral load, increased CD4 counts and regular medical check-ups) and high 
Table 7

Correlations between resting state functional connectivity and cognitive domain scores

\begin{tabular}{|c|c|c|c|c|c|c|}
\hline \multirow{2}{*}{$\begin{array}{l}\text { Cognitive } \\
\text { Domain }\end{array}$} & & \multicolumn{5}{|c|}{ smReHo values } \\
\hline & & $\begin{array}{c}\text { L Inferior } \\
\text { frontal gyrus }\end{array}$ & $\begin{array}{c}\text { L Middle } \\
\text { occipital gyrus }\end{array}$ & $\begin{array}{l}\text { L Caudate } \\
\text { nucleus }\end{array}$ & L Thalamus & R Thalamus \\
\hline \multirow[t]{2}{*}{ Attention } & $\mathrm{HIV+}$ & 0.29 & 0.33 & 0.31 & $0.76^{*}$ & $0.81^{*}$ \\
\hline & HIV- & $-0.75^{*}$ & -0.27 & 0.10 & 0.45 & 0.12 \\
\hline \multirow[t]{2}{*}{ Memory } & $\mathrm{HIV}+$ & 0.02 & 0.26 & 0.12 & 0.33 & 0.38 \\
\hline & HIV- & -0.05 & -0.35 & 0.15 & 0.48 & 0.33 \\
\hline \multirow[t]{2}{*}{ Executive } & $\mathrm{HIV}+$ & -0.02 & 0.48 & 0.05 & 0.64 & $0.71^{*}$ \\
\hline & HIV- & $-0.70^{*}$ & 0.08 & 0.05 & 0.17 & 0.07 \\
\hline \multirow[t]{2}{*}{ Psychomotor } & $\mathrm{HIV+}$ & 0.29 & 0.26 & 0.14 & 0.64 & $0.71^{*}$ \\
\hline & HIV- & -0.43 & 0.52 & -0.15 & -0.25 & -0.08 \\
\hline \multirow[t]{2}{*}{ Semantic } & $\mathrm{HIV}+$ & -0.26 & 0.26 & 0.33 & 0.43 & 0.52 \\
\hline & HIV- & -0.07 & 0.43 & $-0.68^{*}$ & -0.27 & -0.07 \\
\hline
\end{tabular}

Note. All coefficients are Spearman rho coefficients. smReHo - smoothed regional homogeneity; L - left; $\mathrm{R}-$ right; ${ }^{*} p<.05$.

nadir CD4 cell counts in our HIV+ group $(62.5 \%$ had baseline counts $>200$ ), which previously was found to be associated with lower risk of neurocognitive impairment in later stages of infection (Heaton et al., 2010).

Based on Antinori's criteria for HAND classification (2007), one HIV+ participant in our study was classified with asymptomatic neurocognitive impairment (ANI), which refers to cognitive deficits (in at least two domains) that do not interfere with everyday functioning. Thus, our cohort comprised almost exclusively high-functioning HIV-infected adults. Considering the fact that those diagnosed with asymptomatic HAND were previously found to be at a higher risk of progressing to symptomatic HAND than those with unimpaired cognitive functioning (Heaton et al., 2014), the low incidence of HAND in our sample is an optimistic result which suggests that even several years after infection HIV+/HAART+ individuals can retain their cognitive abilities.

The only between-group difference in individual neurocognitive tests was observed in the task engaging visual (visuo-spatial) memory (Corsi, 1972). HIV+ individuals, when compared to HIV- counterparts, showed more difficulties in repeating sequences of 'tapped' blocks in the forward condition (as opposed to the backwards condition). Lower scores may suggest subtle visual/visuo-spatial memory deficits in the HIV+ group. Nevertheless, because of the nature of this task, it cannot be ruled out that deficient performance in that task may be secondary to attentional problems. Impairments in each of these domains (i.e., memory and attention) have been previously reported in studies with HIV+ participants (Woods et al., 2009).

In the Famous Names Recognition Task (FNRT) individuals in both HIV+ and HIV- groups had very high accuracy and comparable reaction time. This is not unexpected taking into account the fact that FNRT was designed as a low-effort semantic task (Douville et al., 2005) and names used in the task are chosen on the basis of their high identification rate (>90\%). This observation is also consistent with findings of studies with people with mild cognitive impairment, at risk of Alzheimer's disease, and healthy comparators, in which, similarly to our results, no between-group differences in FNRT performance were noted (Seidenberg et al., 2009; Woodard et al., 2009). Despite the lack of between-group differences in performance on semantic memory t-fMRI, we noted regional (cortical and subcortical) hypoactivation in the HIV+ group during the task of recognition of famous names. Specifically, in the HIV+ group famous names induced lower activation in the left caudate nucleus, left inferior frontal gyrus, left and right thalamus, and left middle occipital gyrus. These regions are responsible for inhibitory control, language/syntax processing, and sensory and visual processing, among others. Four out of five regions which were found to be hypoactive in the HIV+ group belong to the 'executive network', i.e. the fronto-striatal network (FSN). Therefore, our results add further evidence for HIV-related functional abnormalities in FSN described in the literature (Du Plessis et al., 2014; Hakkers et al., 2017). In the review from 2014, Du Plessis indicated the left inferior frontal gyrus and left caudate nucleus as the most vulner-
Brain activity in HIV infection 
Anna R. Egbert, Agnieszka Pluta, Marta Sobańska, Natalia Gawron, Bogna SzymańskaKotwica,

Emilia Łojek, Harmonia Group able to HIV infection. Both of these regions showed between-group differences in activation in our study. In addition to hypoactivation within the FSN, we also noted decreased activity in the left middle occipital gyrus, which is a region particularly implicated in visual processing (Yang, Deng, Xing, Xia, \& Li, 2015).

Worth mentioning is the fact that although the majority of studies with HIV-positive individuals report hyperactivation within the FSN (Du Plessis et al., 2014; Hakkers et al., 2017), which is usually interpreted as functional compensation (i.e. increased activation to counteract subtle HIV-related changes within the brain), we observed lower regional brain activation during famous names recognition in the $\mathrm{HIV}+$ group (compared to healthy comparators). According to Melrose (2008), who also noted decreased activation in e.g. the left caudate nucleus in HIV-infected participants, regional hypoactivation may indicate HIV-related functional reorganization (such as reduced inter-regional connectivity).

We further analyzed spontaneous local functional connectivity in the brain regions showing lower activity during task execution. Our analyses did not reveal differences between HIV+ and HIV- individuals in the level of smReHo in the five identified FSN areas. However, there were positive relationship between smReHo in those regions and cognitive outcomes in HIV+/HAART+ while no such relationships were observed in the HIV- group.

As no cognitive decline was observed in our HIV+ group, we speculated that the positive association between local activation and performance on particular cognitive domains in the HIV+ group may indicate HIV-related functional compensation. In particular, in HIV+ participants higher local functional connectivity in the left and right thalamus was positively related to better outcomes on cognitive tests measuring attention, executive functions and psychomotor skills. Meanwhile, in healthy comparators, we observed that local functional connectivity in the left caudate and left IFG was negatively related to cognitive scores on tests assessing semantic skills, attention and executive functions. These findings suggest functional brain reorganization in HIV+/cART+ patients. Our results support previous findings of functional brain network reorganization in the $\mathrm{HIV+/cART+}$ patient population in early stages of HAND (Abidin et al., 2018). Previous research showed a general reorganization of functional network properties in relationship to executive function (Abidin et al., 2018). Here, we show that the involvement of brain regions in attention and executive function is relocated to more subcortical structures such as the thalamus in HIV+/cART+ individuals. This functional shift seems to be successful in supporting cognitive performance at an optimal level as we did not observe significant deterioration in these cognitive functions in our patient sample as compared to healthy individuals.

\section{LIMITATIONS}

Due to the small sample size, our analyses should be treated with caution. With less than 10 participants in each group, the statistical power of our study is limited. Future research is needed in order to validate the current results on a larger sample.

\section{ACKNOWLEDGMENTS}

This study was supported by the Polish National Science Center (grant\# UMO-2012/06/M/H56/00316). The authors report no conflicts of interest. Harmonia-3 Group: Tomasz Wolak, Łukasz Okruszek, Ewa Firląg-Burkacka, Andrzej Horban, Przemysław Bieńkowski, Halina Sienkiewicz-Jarosz, Anna ŚcińskaBieńkowska, Joanna Poweska, Robert Bornstein, Stephen Rao.

\section{REFERENCES}

Abidin, A. Z., DSouza, A. M., Nagarajan, M. B., Wang, L., Qiu, X., Schifitto, G., \& Wismüller, A. (2018). Alteration of brain network topology in HIV-associated neurocognitive disorder: a novel functional connectivity perspective. Neurolmage: Clinical, 17, 768-777. https://doi.org/10.1016/j.nicl.2017.11.025

Antinori, A., Arendt, G., Becker, J. T., Brew, B. J., Byrd, D. A., Cherner, M., Clifford, D. B., Cinque, P., Epstein, L. G., Goodkin, K., Gisslen, M., Grant, I., Heaton, R. K., Joseph, J., Marder, K., Marra, C. M., McArthur, J. C., Nunn, M., Price, R. W., Pulliam, L., Robertson, K. R., Sacktor, N., Valcour, V., \& Wojna, V. E. (2007). Updated research nosology for HIV-associated neurocognitive disorders. Neurology, 69, 1789-1799. https://doi.org/10.1212/01.WNL. $0000287431.88658 .8 \mathrm{~b}$

Arthurs, O. J., \& Boniface, S. (2002). How well do we understand the neural origins of the $f M R I$ BOLD signal? Trends in Neurosciences, 25, 27-31. https:// doi.org/10.1016/S0166-2236(00)01995-0

Ashburner, J., Barnes, G., Chen, C., Daunizeau, J., Flandin, G., Friston, K., ... \& Penny, W. (2017). SPM12 Manual. Retrieved from http://www.fil.ion. ucl.ac.uk/spm/ [accessed April 4, 2018].

Birn, R. M., Molloy, E. K., Patriat, R., Parker, T., Meier, T. B., Kirk, G. R., Nair, V. A., Meyerand, M. E., \& Prabhakaran, V. (2013). The effect of scan length on the reliability of resting-state $\mathrm{fMRI}$ connectivity estimates. Neurolmage, 83, 550-558. https:// doi.org/10.1016/j.neuroimage.2013.05.099

Biswal, B., Zerrin Yetkin, F., Haughton, V. M., \& Hyde, J. S. (1995). Functional connectivity in the motor cortex of resting human brain using echoplanar MRI. Magnetic Resonance in Medicine, 34, 537-541. https://doi.org/10.1002/mrm.1910340409 
Brett, M., Anton, J. L., Valabregue, R., \& Poline, J. B. (2002). Region of interest analysis using the MarsBar toolbox for SPM 99. Neurolmage, 16, 497.

Brzeziński, J., Gaul, M., Hornowska, E., Jaworowska, A., Machowski, A., \& Zakrzewska, M. (2004). Skala Inteligencji D. Wechslera dla dorostych. Wersja Zrewidowana. WAIS-R(PL) [The Wechsler Adult Intelligence Scale. Revised Version. WAIS-R(PL)]. Warszawa: Pracownia Testów Psychologicznych PTP.

Chelune, G. J., Heaton, R. K., \& Lehman, R. A. W. (1986). Neuropsychological and personality correlates of patients' complaints of disability. In G. Goldstein \& R. E. Tarter (Eds.), Advances in clinical neuropsychology (Vol. 3, pp. 95-126). New York, NY: Plenum Press.

Cole, M. W., Bassett, D. S., Power, J. D., Braver, T. S., \& Petersen, S. E. (2014). Intrinsic and task-evoked network architectures of the human brain. Neuron, 83, 238-251. https://doi.org/10.1016/j.neuron. 2014.05.014

Corsi, P. (1972). Human memory and the medial temporal region of the brain. Dissertation Abstracts International, 34, 891.

D’Elia, L., \& Satz, P. (2000). Color trails test. Lutz, FL: Psychological Assessment Resources.

Delis, D. C., Kramer, J. H., Kaplan, E., \& Ober, B. A. (2000). CVLT-II: California verbal learning test: adult version. San Antonio, TX: Psychological Corporation.

Di, X., \& Biswal, B. B. (2015). Characterizations of resting-state modulatory interactions in human brain. Journal of Neurophysiology, 114, 2785-2796. https://doi.org/10.1152/jn.00893.2014.

Dosenbach, N. U., Nardos, B., Cohen, A. L., Fair, D. A., Power, J. D., Church, J. A., Nelson, S. M., Wig, G. S., Vogel, A. C., Lessov-Schlaggar, C. N., Barnes, K. A., Dubis, J. W., Feczko, E., Coalson, R. S., Pruett, J. R., Barch, D. M., Petersen, S. E., \& Schlaggar, B. L. (2010). Prediction of individual brain maturity using fMRI. Science, 329, 1358-1361. https://doi. org/10.1126/science. 1194144

Douville, K., Woodard, J. L., Seidenberg, M., Miller, S. K., Leveroni, C. L., Nielson, K. A., Franczak, M., Antuono, P., \& Rao, S. M. (2005). Medial temporal lobe activity for recognition of recent and remote famous names: an event-related fMRI study. Neuropsychologia, 43, 693-703. https://doi.org/10.1016/j. neuropsychologia.2004.09.005

Du Plessis, S., Vink, M., Joska, J. A., Koutsilieri, E., Stein, D. J., \& Emsley, R. (2014). HIV infection and the fronto-striatal system: a systematic review and meta-analysis of fMRI studies. AIDS, 28, 803-811. https://doi.org/10.1097/QAD.0000000000000151

Eaton, W. W., Smith, C., Ybarra, M., Muntaner, C., \& Tien, A. (2004). Center for Epidemiologic Studies Depression Scale: review and revision (CESD and CESD-R). In M. E. Maruish (Ed.), The use of psychological testing for treatment planning and outcomes assessment: Instruments for adults (pp. 363-377). Mahwah, NJ: Lawrence Erlbaum Associates Publishers.

Egbert, A. R., Biswal, B., Karunakaran, K., Gohel, S., Pluta, A., Wolak, T., Szymańska, B., Firląg-Burkacka, E., Sobańska, M., Gawron, N., Bieńkowski, P., Sienkiewicz-Jarosz, H., Ścińska-Bieńkowska, A., Bornstein, R., Rao, S., \& Łojek, E. (2018). Age and HIV effects on resting state of the brain in relationship to neurocognitive functioning. Behavioural Brain Research, 344, 20-27. https://doi.org/10.1016/j. bbr.2018.02.007

Folstein, M. F., Folstein, S. E., \& McHugh, P. R. (1975). "Mini-mental state": a practical method for grading the cognitive state of patients for the clinician. Journal of Psychiatric Research, 12, 189-198. https://doi.org/10.1016/0022-3956(75)90026-6

Fox, M. D., \& Raichle, M. E. (2007). Spontaneous fluctuations in brain activity observed with functional magnetic resonance imaging. Nature Reviews Neuroscience, 8, 700-711. https://doi.org/10.1038/nrn2201

Geerligs, L., Rubinov, M., \& Henson, R. N. (2015). State and trait components of functional connectivity: Individual differences vary with mental state. Journal of Neuroscience, 35, 13949-13961. https://doi.org/10.1523/JNEUROSCI.1324-15.2015

Gordon, E. M., Laumann, T. O., Gilmore, A. W., Newbold, D. J., Greene, D. J., Berg, J. J., Ortega, M., HoytDrazen, C., Gratton, C., Sun, H., Hampton, J. M., Coalson, R. S., Nguyen, A. L., McDermott, K. B., Shimony, J. S., Snyder, A. Z., Schlaggar, B. L., Petersen, S. E., Nelson, S. M., \& Dosenbach, N. U. F. (2017). Precision functional mapping of individual human brains. Neuron, 95, 791-807. https://doi. org/10.1016/j.neuron.2017.07.011

Gray, L. R., Roche, M., Flynn, J. K., Wesselingh, S. L., Gorry, P. R., \& Churchill, M. J. (2014). Is the central nervous system a reservoir of HIV-1? Current Opinion in HIV and AIDS, 9, 552-558. https://doi. org/10.1097/COH.0000000000000108

Hakkers, C. S., Arends, J. E., Barth, R. E., Du Plessis, S., Hoepelman, A. I. M., \& Vink, M. (2017). Review of functional MRI in HIV: Effects of aging and medication. Journal of Neurovirology, 23, 20-32. https:// doi.org/10.1007/s13365-016-0483-y

Heaton, R. K. (1981). A manual for the Wisconsin Card Sorting Test. Lutz, FL: Psychological Assessment Resources.

Heaton, R. K., Clifford, D. B., Franklin, D. R., Woods, S. P., Ake, C., Vaida, F., Ellis, R. J., Letendre, S. L., Marcotte, T. D., Atkinson, J. H., RiveraMindt, M., Vigil, O. R., Taylor, M. J., Collier, A. C., Marra, C. M., Gelman, B. B., McArthur, J. C., Morgello, S., Simpson, D. M., McCutchan, J. A., Abramson, I., Gamst, A., Fennema-Notestine, C., Jernigan, T. L., Wong, J., \& Grant, I. (2010). HIV-associated neurocognitive disorders persist in the era of potent antiretroviral therapy: CHARTER Study.
Brain activity in HIV infection 
Anna R. Egbert, Agnieszka Pluta, Marta Sobańska, Natalia Gawron, Bogna SzymańskaKotwica,

Emilia Łojek, Harmonia Group
Neurology, 75, 2087-2096. https://doi.org/10.1212/ WNL.0b013e318200d727

Heaton, R. K., Franklin, D. R., Ellis, R. J., McCutchan, J. A., Letendre, S. L., LeBlanc, S., Corkran, S. H., Duarte, N. A., Clifford, D. B., Woods, S. P., Collier, A. C., Marra, C. M., Morgello, S., Mindt, M. R., Taylor, M. J., Marcotte, T. D., Atkinson, J. H., Wolfson, T., Gelman, B. B., McArthur, J. C., Simpson, D. M., Abramson, I., Gamst, A., Fennema-Notestine, C., Jernigan, T. L., Wong, J., \& Grant, I. (2011). HIV-associated neurocognitive disorders before and during the era of combination antiretroviral therapy: Differences in rates, nature, and predictors. Journal of Neurovirology, 17, 3-16. https://doi.org/10.1007/s13365-010-0006-1

Heaton, R. K., Franklin Jr, D. R., Deutsch, R., Letendre, S., Ellis, R. J., Casaletto, K., Marquine, M. J., Woods, S. P., Vaida, F., Atkinson, J. H., Marcotte, T. D., McCutchan, J. A., Collier, A. C., Marra, C. M., Clifford, D. B., Gelman, B. B., Sacktor, N., Morgello, S., Simpson, D. M., Abramson, I., Gamst, A. C., Fennema-Notestine, C., Smith, D. M., \& Grant, I. (2014). Neurocognitive change in the era of HIV combination antiretroviral therapy: the longitudinal CHARTER study. Clinical Infectious Diseases, 60, 473-480. https://doi.org/10.1093/cid/ ciu862

Ipser, J. C., Brown, G. G., Bischoff-Grethe, A., Connolly, C. G., Ellis, R. J., Heaton, R. K., Grant, I., \& Translational Methamphetamine AIDS Research Center (TMARC) Group (2015). HIV infection is associated with attenuated frontostriatal intrinsic connectivity: a preliminary study. Journal of the International Neuropsychological Society, 21, 203-213. https://doi.org/10.1017/S1355617715000156

Janssen, M. A., Hinne, M., Janssen, R. J., van Gerven, M. A., Steens, S. C., Góraj, B., Koopmans, P. P., \& Kessels, R. P. (2017). Resting-state subcortical functional connectivity in HIV-infected patients on long-term cART. Brain Imaging and Behavior, 11, 1555-1560. https://doi.org/10.1007/s11682-0169632-4

Jaworowska, A. (2002). Wisconsin Card Sorting Test (WCST). Manual. Warszawa: Pracownia Testów Psychologicznych PTP.

Koziara, K. (2016). Ocena depresyjności w populacji. Psychometryczna ocena polskiej wersji skali CESD-R [Assessment of depressiveness in population. Psychometric evaluation of the Polish version of the CESD-R]. Psychiatria Polska, 50, 1109-1117. https://doi.org/10.12740/PP/61614

Lacadie, C. M., Fulbright, R. K., Rajeevan, N., Constable, R. T., \& Papademetris, X. (2008). More accurate Talairach coordinates for neuroimaging using non-linear registration. Neurolmage, 42, 717-725. https://doi.org/10.1016/j.neuroimage.2008.04.240

Łojek, E., \& Stańczak, J. (2005). Test Ptynności Figuralnej Ruffa. Podręcznik [Ruff's Figural Fluency Test.
Manual]. Warszawa: Pracownia Testów Psychologicznych PTP.

Łojek, E., \& Stańczak, J. (2012). CTT - Kolorowy Test Połączeń wersja dla Dorostych [The Color Trail Test for Adults]. Warszawa: Pracownia Testów Psychologicznych PTP.

Łojek, E., Stańczak, J., Delis, D. C., Kramer, J. H., \& Ober, B. A. (2010). Podręcznik do kalifornijskiego testu uczenia się językowego CVLT Deana $C$. Delisa, Joela H. Kramera, Edith Kaplan i Beth A. Ober: polska normalizacja [Manual of the California Verbal Learning Test CVLT by Dean C. Delis, Joel H. Kramer, Edith Kaplan and Beth A. Ober: Polish normalization]. Warszawa: Pracownia Testów Psychologicznych PTP.

Matthews, C. G., \& Klove, H. (1964). Instruction manual for the adult neuropsychology test battery. Madison, WI: University of Wisconsin Medical School.

McArthur, J. C., \& Brew, B. J. (2010). HIV-associated neurocognitive disorders: Is there a hidden epidemic? AIDS, 24, 1367-1370. https://doi.org/10.1097/ QAD.0b013e3283391d56

Melrose, R. J., Tinaz, S., Castelo, J. M. B., Courtney, M. G., \& Stern, C. E. (2008). Compromised fronto-striatal functioning in HIV: an fMRI investigation of semantic event sequencing. Behavioural Brain Research, 188, 337-347. https://doi. org/10.1016/j.bbr.2007.11.021

Nath, A. (2015). Eradication of human immunodeficiency virus from brain reservoirs. Journal of Neurovirology, 21, 227-234. https://doi.org/10.1007/s13365014-0291-1

Ortega, M., Brier, M. R., \& Ances, B. M. (2015). Effects of HIV and combination antiretroviral therapy (cART) on cortico-striatal functional connectivity. AIDS, 29, 703-712. https://doi.org/10.1097/ QAD.0000000000000611

Rao, S. M., Bonner-Jackson, A., Nielson, K. A., Seidenberg, M., Smith, J. C., Woodard, J. L., \& Durgerian, S. (2015). Genetic risk for Alzheimer's disease alters the five-year trajectory of semantic memory activation in cognitively intact elders. Neurolmage, 111, 136146. https://doi.org/10.1016/j.neuroimage.2015.02.011

Ruff, R. M. (1996). Ruff figural fluency test: professional manual. Lutz, FL: Psychological Assessment Resources.

Seidenberg, M., Guidotti, L., Nielson, K. A., Woodard, J. L., Durgerian, S., Antuono, P., Zhang, Q., \& Rao, S. M. (2009). Semantic memory activation in individuals at risk for developing Alzheimer disease. Neurology, 73, 612-620. https://doi.org/10.1212/ WNL.0b013e3181b389ad

Stańczak, J. (2010). MMSE: polska normalizacja [MMSE: Polish normalization]. Warszawa: Pracownia Testów Psychologicznych PTP.

Szepietowska, E. M., \& Gawda, B. (2011). Ścieżkami fluencji stownej [The pathways of verbal fluency]. Lublin: Wydawnictwo UMCS. 
Tavor, I., Jones, O. P., Mars, R. B., Smith, S. M., Behrens, T. E., \& Jbabdi, S. (2016). Task-free MRI predicts individual differences in brain activity during task performance. Science, 352, 216-220. https://doi.org/10.1126/science.aad8127

UNAIDS (2017). AIDSinfo. Retrieved from http://aidsinfo.unaids.org [accessed January 20, 2019].

Wechsler, D. (1981). WAIS-R manual: Wechsler adult intelligence scale-revised. San Antonio, TX: Psychological Corporation.

Wellcome Department of Imaging Neuroscience London (2014). Statistical Parametric Mapping Version 12. Retrieved from http://www.fil.ion.ucl.ac.uk/ spm/software/

Woodard, J. L., Seidenberg, M., Nielson, K. A., Antuono, P., Guidotti, L., Durgerian, S., Zhang, Q. Lancaster, M., Hantke, N., Butts, A., \& Rao, S. M. (2009). Semantic memory activation in amnestic mild cognitive impairment. Brain, 132, 2068-2078. https://doi.org/10.1093/brain/awp157

Woods, S. P., Moore, D. J., Weber, E., \& Grant, I. (2009). Cognitive neuropsychology of HIV-associated neurocognitive disorders. Neuropsychology Review, 19, 152-168. https://doi.org/10.1007/ s11065-009-9102-5

Yang, Y. L., Deng, H. X., Xing, G. Y., Xia, X. L., \& Li, H. F. (2015). Brain functional network connectivity based on a visual task: visual information processing-related brain regions are significantly activated in the task state. Neural Regeneration Research, 10, 298-307. https://doi.org/10.4103/1673-5374.152386 